\title{
Timing of surgery in traumatic spinal cord injury: a national, multidisciplinary survey
}

\author{
P. V. ter Wengel ${ }^{1,7}$ (1) $\cdot$ R. E. Feller ${ }^{1} \cdot$ A. Stadhouder ${ }^{2} \cdot$ D. Verbaan ${ }^{1,3} \cdot$ F. C. Oner ${ }^{4} \cdot$ J. C. Goslings ${ }^{5} \cdot$ W. P. Vandertop ${ }^{1,3,6}$
}

Received: 31 October 2017 / Revised: 1 February 2018 / Accepted: 13 March 2018 / Published online: 23 March 2018

(c) The Author(s) 2018

\begin{abstract}
Purpose The optimal surgical timeframe for neurological recovery in traumatic spinal cord injury (tSCI) still remains unknown. Recent guidelines have recommended performing surgery within $24 \mathrm{~h}$ for all patients with tSCI regardless of initial neurological deficit. It remains unclear whether patients with complete, incomplete tSCI, or traumatic central cord injury (TCCI) will experience the same degree of improvement after urgent surgical intervention. We investigated if the severity of initial neurological injury influenced surgeons on their decision-making of surgical timing in tSCI.

Methods With a web-based survey, we investigated the current opinion in The Netherlands on timing of surgical decompression and stabilization, depending on the initial degree of neurological injury.

Results Surgeons prefer to perform more urgent surgery for incomplete tSCI compared to complete tSCI. In addition, $43 \%$ of patients with complete tSCI are not preferably operated within the recommended $24 \mathrm{~h}$. Even though TCCI is the most common form of incomplete tSCI, these patients are preferably managed less urgently than patients with other types of incomplete tSCI.

Conclusion The severity of initial neurological injury seems to play an important role in the urgency of surgical timing for tSCI. A substantial number of patients with complete tSCI are not preferably treated within the recommended surgical timeframe, while patients with incomplete tSCI are preferably operated far more urgent than recommended in the current guidelines.
\end{abstract}

Graphical abstract These slides can be retrieved under Electronic Supplementary Material.
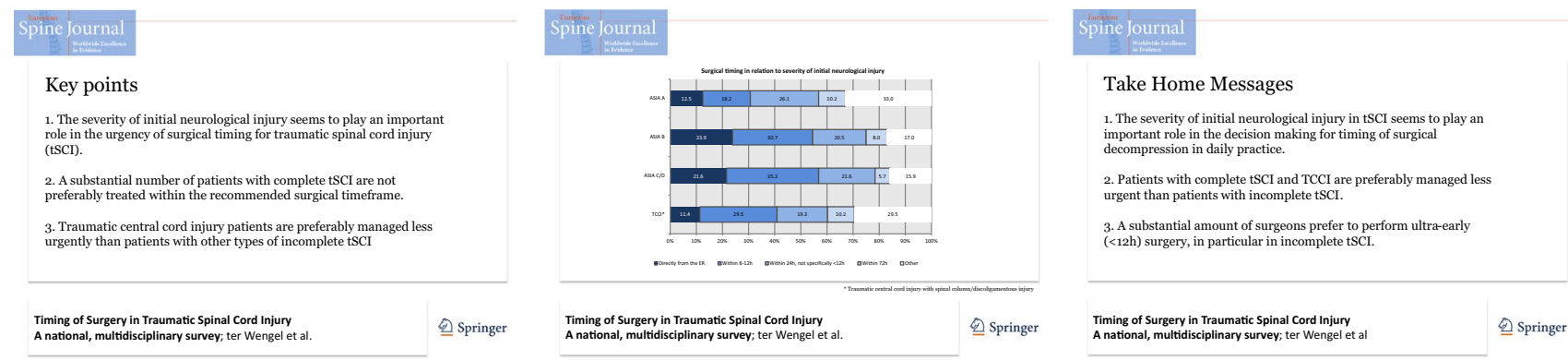

Keywords Spinal cord injuries $\cdot$ Timing $\cdot$ Decompression $\cdot$ Stabilization $\cdot$ Survey $\cdot$ Spine trauma

Electronic supplementary material The online version of this article (https://doi.org/10.1007/s00586-018-5551-y) contains supplementary material, which is available to authorized users.

W. P. Vandertop

wp.vandertop@vumc.nl; w.p.vandertop@amc.nl

Extended author information available on the last page of the article

\section{Introduction}

Traumatic spinal cord injury (tSCI) is a devastating event, affecting a patient's life in innumerable ways [1]. Surgical decompression seems to have a beneficial effect on the neurological outcome in the acutely injured spinal cord $[2,3]$. 
However, the optimal surgical timeframe for maximizing neurological recovery remains unclear, as well as the impact of urgent surgery in complete compared to incomplete tSCI [4-6].

The Surgical Timing in Acute Spinal Cord Injury Study study (STASCIS) was the first large, international, prospective cohort study in cervical tSCI patients to investigate the effect of surgical timing on neurological outcome [3]. This study showed a beneficial effect on neurological outcome when surgical decompression and stabilization was performed within $24 \mathrm{~h}$ after injury compared to surgery performed after $24 \mathrm{~h}$, in both patients with complete and incomplete tSCI.

Recently, some smaller studies have also confirmed that neurological recovery is not only limited to patients with incomplete tSCI [7, 8]. This effect was also seen in complete tSCI when surgery was performed urgently [4]. In addition, recent international guidelines recommend performing surgery within $24 \mathrm{~h}$ for tSCI regardless of initial neurological status $[9,10]$.

While the optimal surgical timeframe is still unclear, current studies are investigating even earlier surgical timeframes $[5,6,8]$.

We investigated to what extent recent international guidelines are implemented in daily practice and whether the initial neurological exam has an impact on the current decisionmaking in surgical management of tSCI patients [9].

\section{Methods}

Since the surgical treatment of patients with tSCI in The Netherlands is primarily performed in multidisciplinary teams, a multidisciplinary group from three university medical centers (VU University Medical Center and Academic Medical Center both in Amsterdam, and University Medical Center Utrecht), consisting of two neurosurgeons, a trauma surgeon and two orthopedic surgeons, developed a short, web-based, survey on the timing of surgery in tSCI patients (see supplementary appendix). We conducted the survey between November 2016 and January 2017. The survey was sent to all 138 Dutch neurosurgeons, member of the
Dutch Society of Neurological Surgeons of which 59 were also member of the Dutch Spine Society (DSS). In addition, the survey was sent to all 88 orthopedic surgeons who are members of the DSS and 13 trauma surgeons at the VU University Medical Center and University Medical Center in Groningen, where trauma surgeons participate in acute surgical management of patients with tSCI.

The survey comprised of 15 questions, divided into three parts, and focused on the influence of the level and severity of neurological injury on surgical timing. The first part consisted of seven general questions on case volume and role of the surgeon in the management of tSCI patients. The second part contained five questions regarding one hypothetical case with traumatic spinal cord injury with traumatic instability of the spine and four different degrees of neurological injury [ASIA A, B, C/D, and traumatic central cord injury (TCCI)], and a second hypothetical case with traumatic central cord injury without spinal instability. Surgeons were asked to choose a specific timeframe to perform surgical decompression and stabilization in these hypothetical patients, who were hemodynamically stable and did not have any contra-indications for urgent surgery. The surgical timing was categorized as ultra-early (directly from the ER or within 8-12 h after trauma), early (within $24 \mathrm{~h}$, not specifically $<12 \mathrm{~h}$ ), late (within $72 \mathrm{~h}$ ), or other (e.g., timing depending on logistics or deterioration).

The third part consisted of three questions of surgical timing and the level of injury, since most of the evidence for urgent surgical decompression comes from studies in cervical tSCI patients only. Respondents were asked to comment on their preferred surgical timing for each case.

Spinal cord injury was divided into complete versus incomplete injury, according to the American Spinal Injury Association (ASIA) Impairment Scale (Table 1) [11]. Full description was provided for each grade, since not all surgeons use this classification likewise, or on a daily basis.

Traumatic central cord injury (TCCI), the most common form of an incomplete (ASIA C or D) spinal cord injury, is characterized by motor impairment in upper extremities worse than in lower extremities. Since a clear distinction is made in daily practice between ASIA C/D and TCCI, we asked respondents to comment separately on their surgical

Table 1 ASIA classification

\begin{tabular}{ll}
\hline & ASIA classification \\
\hline ASIA A & Complete spinal cord motor injury, including complete sensory injury \\
ASIA B & Complete spinal cord motor injury with preservation of sacral sensation $(\mathrm{S} 4,5)$ \\
ASIA C & Incomplete spinal cord motor injury, with $<$ MRC3 (motion against gravity is not possible) in $>50 \%$ of all key muscles \\
ASIA D & Incomplete spinal cord motor injury, with $\geq$ MRC3 (motion against gravity is possible) in $>50 \%$ of all key muscles \\
ASIA E & No motor or sensory spinal cord injury \\
TCCI & Motor impairment is worse in upper extremities than in lower extremities $(10$ MRC points less in arms than in legs) \\
\hline
\end{tabular}


timing for this specific subtype of incomplete tSCI. We made a distinction between TCCI with and without spinal instability, as TCCI more often presents in patients with preexisting spinal canal stenosis and a mild trauma. This last entity is usually thought to harbor an equal, or better, prognosis with non-operative management than surgery.

We analyzed all responses on surgical timing for all grades of tSCI and stratified responders by specialty and whether they had a spinal subspecialization.

\section{Results}

With 88 participants [59/88 (67\%) neurosurgeons, 23/88 (26\%) orthopedic surgeons, and 6/88 (7\%) trauma surgeons], there was an overall response rate of $37 \%$ of which $67 \%$ were spinal subspecialized. Spinal surgery was the subspecialty of $31 / 59$ (53\%) neurosurgeons, $23 / 23$
(100\%) orthopedic surgeons, and 5/6 (83\%) trauma surgeons. Thirty-eight $(43 \%)$ respondents reported an estimated annual incidence of 10-20 patients with tSCI at their center and $21(24 \%)$ an estimated annual incidence of $>20$ tSCI patients (Suppl. 1).

\section{Timing of surgery in $\mathrm{tSCl}$ and relation to the severity of neurological injury}

Most surgeons prefer to perform surgery within $24 \mathrm{~h}$ for tSCI. A distinction in surgical timing is made based upon the initial neurological injury, since only $57 \%$ prefer to perform surgery within $24 \mathrm{~h}$ for complete ASIA A tSCI patients in comparison to $75 \%$ for ASIA B and $78 \%$ for ASIA C/D (Fig. 1).

For incomplete tSCI, a substantial number of surgeons $(56 \%)$ prefer to perform ultra-early $(<12 \mathrm{~h})$ surgery, in contrast to $31 \%$ for complete ASIA A tSCI.

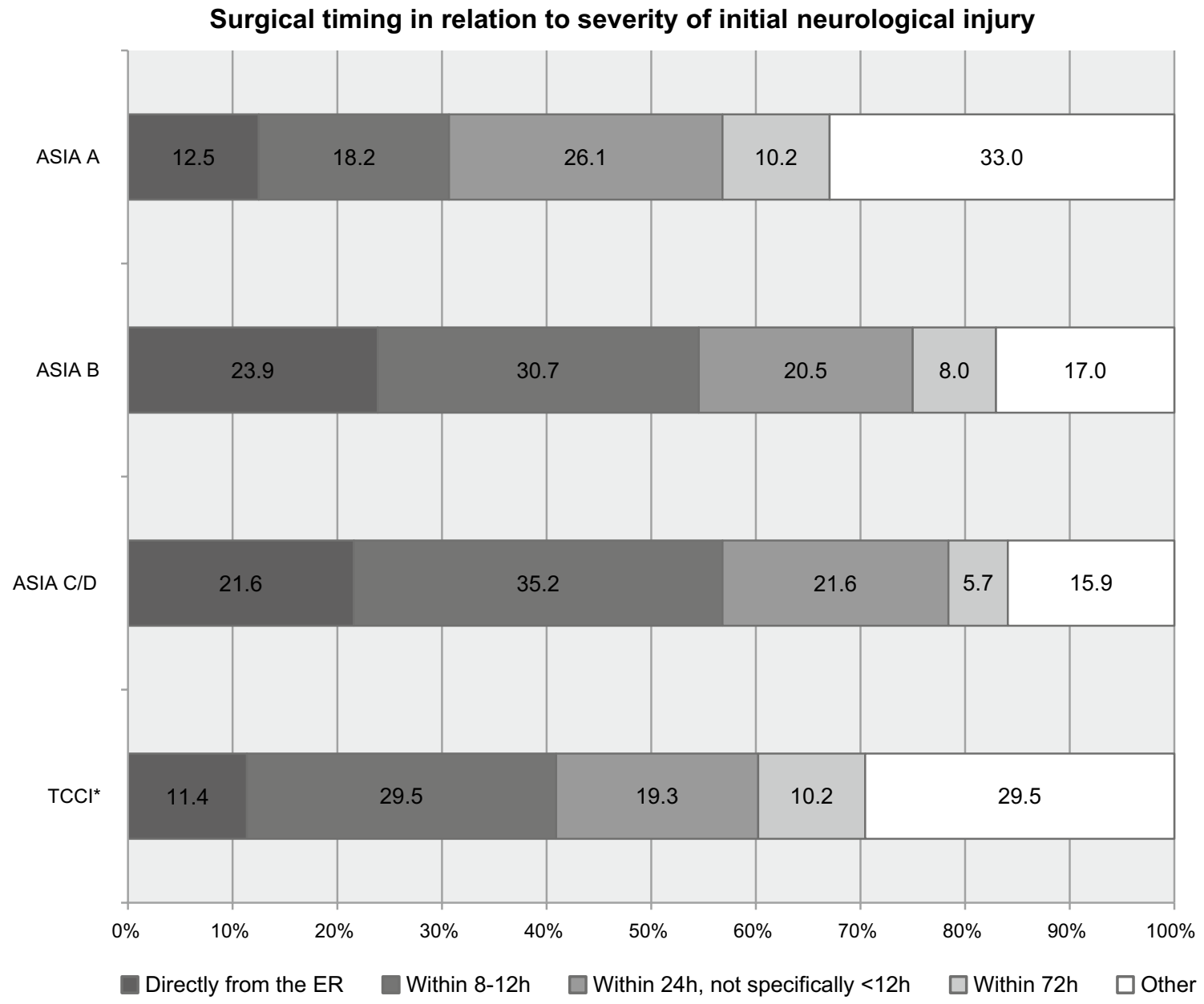

Fig. 1 Surgical timing in relation with severity of initial neurological injury. Other includes respondents who did not choose a specific timeframe, found logistics or deterioration important or were not involved in the decision-making on surgical timing. TCCI*: TCCI with spinal column/discoligamentous injury 


\section{Timing of surgery in traumatic central cord injury (TCCI)}

The timing of surgery in TCCI with spinal column and/ or discoligamentous injury differed when compared to the ASIA C/D patients (61 and $78 \%<24 \mathrm{~h}$, respectively) and showed more similarity to the surgical timing in complete ASIA A tSCI $(57 \%<24 \mathrm{~h})$. Moreover, TCCI patients without spinal column and/or discoligamentous injury were preferably treated far less urgently $(44 \%<24$ h) (Fig. 2; Suppl. 2).

\section{Timing in relationship to spinal subspecialization and surgical specialty}

Subspecialized spine surgeons preferred to surgically treat the majority of all tSCI patients within $24 \mathrm{~h}$, regardless of severity of neurological injury in contrast to their colleagues (Fig. 3). They did, however, make a distinction to perform ultra-early $(<12 \mathrm{~h})$ surgery based on the completeness of neurological injury (40\% for complete ASIA A versus $62 \%$ approximately for incomplete tSCI). This tendency towards ultra-early surgery was also visible in TCCI patients with and without spinal instability (Figs. 3, 4).

Non-spinal subspecialized surgeons preferred to surgically treat complete ASIA A tSCI far less urgently than their spinal subspecialized colleagues (41 and $65 \%<24 \mathrm{~h}$, respectively; Suppl. 3). This difference was also present in patients with TCCI with spinal instability (Fig. 3). We additionally observed a difference in timing between specialties, where orthopedic surgeons tended to prefer more urgent surgical interventions in patients with complete tSCI than neurosurgeons (Suppl. 4). This difference remained after correcting for spinal subspecialization (Table 2).

\section{Timing of surgery in relation with the level of injury and ideal surgical timing}

The majority of the respondents applied the same surgical timing, as for cervical injuries, in patients with thoracic and conus/cauda injury ( 83 and $74 \%$, respectively). Two-third $(55 / 88)$ of the respondents would not ideally perform surgery for any form of tSCI in a more urgent matter. Most of the respondents who commented on their choice $(13 / 55)$ found the evidence too scant to change their current time management for tSCI.

\section{Discussion}

Our survey showed that the severity of initial neurological injury seems to play an important role in the decision-making for timing of surgical decompression, since patients with incomplete tSCI are preferably operated in a more urgent fashion than patients with complete tSCI. While patients with incomplete tSCI are preferably treated more urgent than the recommended international guideline, only $57 \%$ of patients with complete tSCI are preferably surgically treated within $24 \mathrm{~h}$. In contrast to patients with incomplete tSCI, patients with traumatic central cord injury (TCCI) are

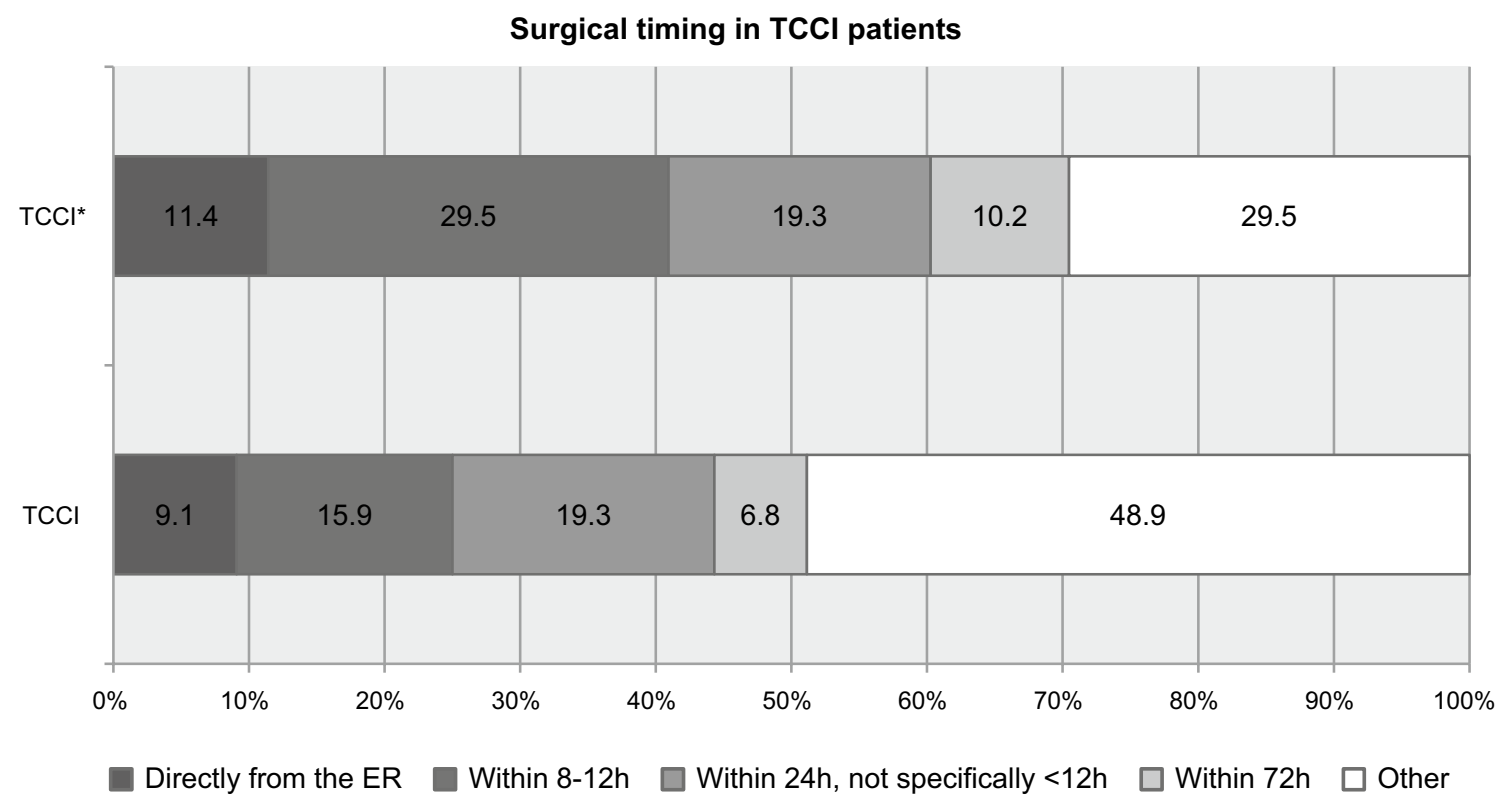

Fig. 2 Surgical timing in TCCI. TCCI*: TCCI with spinal column/discoligamentous injury. Other includes respondents who did not choose a specific timeframe, found logistics or deterioration important or were not involved in the decision-making on surgical timing 


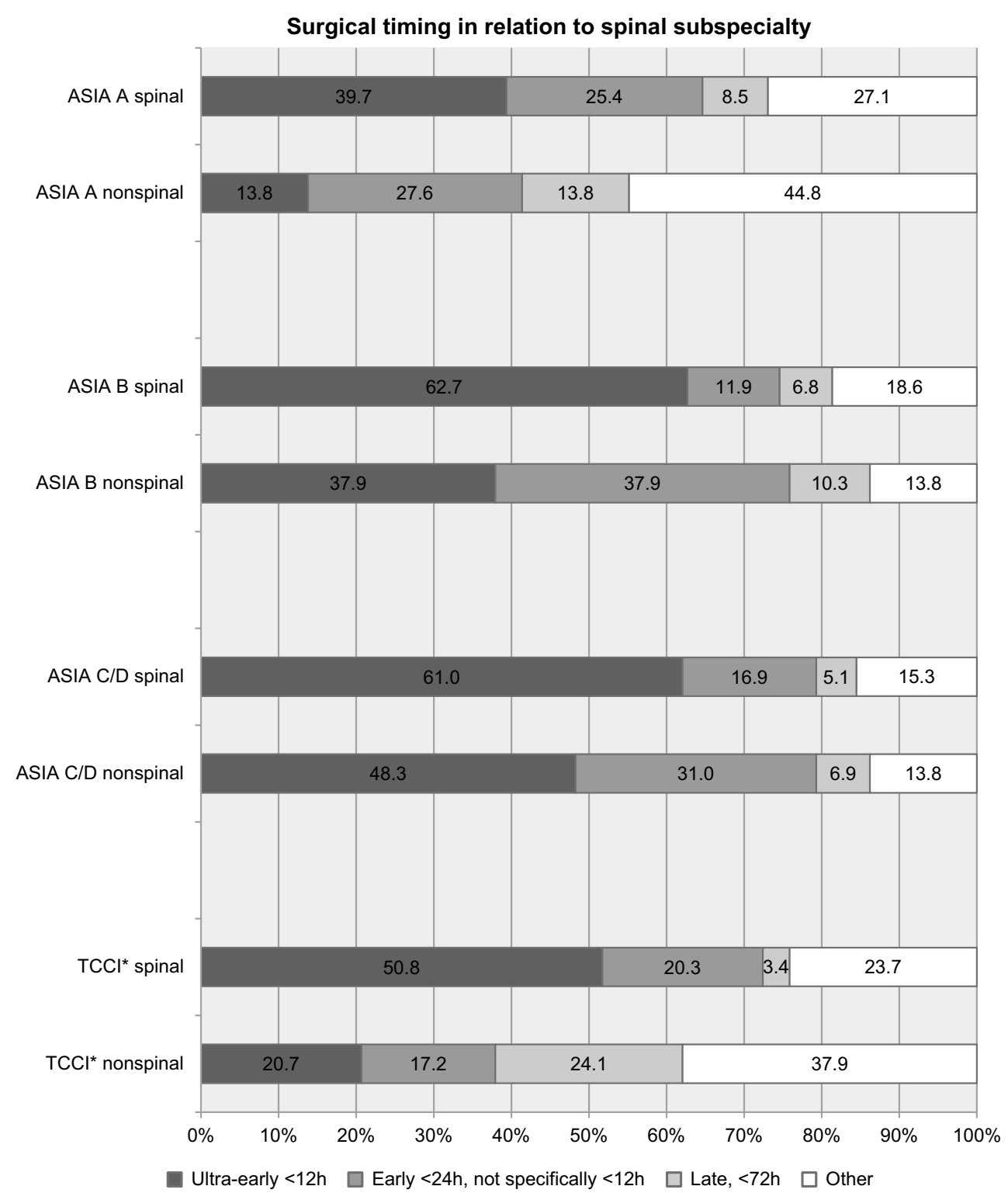

Fig. 3 Surgical timing in relation with spinal subspecialization. TCCI*: TCCI with spinal column/discoligamentous injury

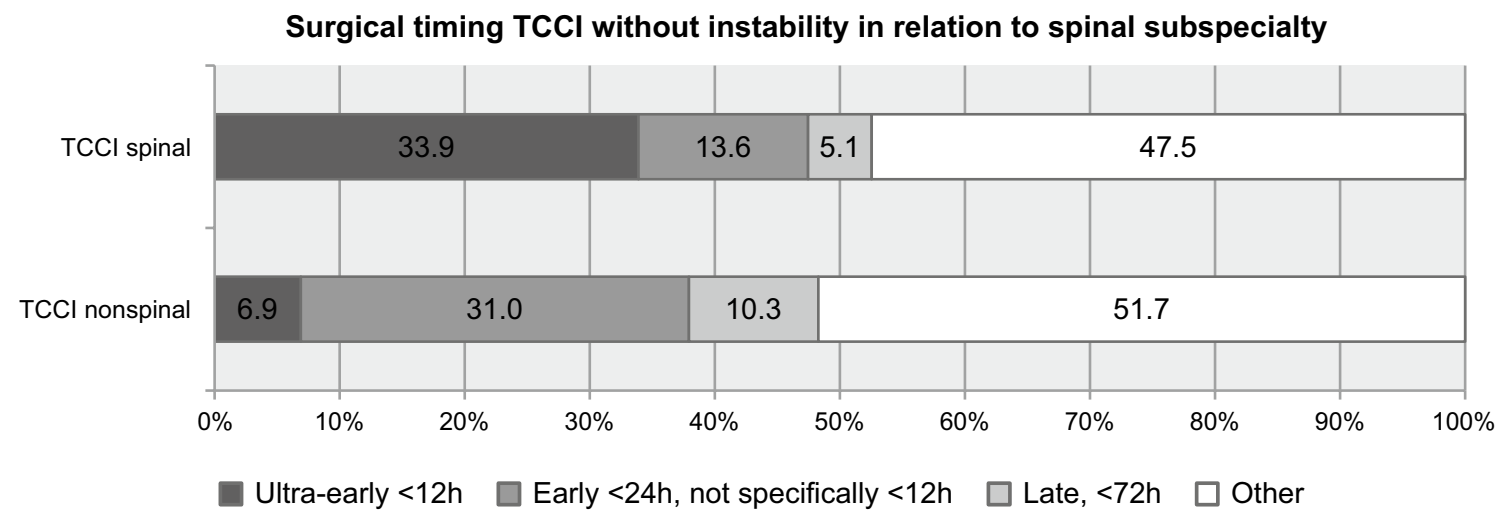

Fig. 4 Preferred surgical timing in TCCI without spinal instability. Other includes surgeons who were not involved in the treatment of these patients or found logistics or deterioration important for surgical timing 
Table 2 Preferred surgical timing in patients with ASIA A, $\mathrm{B}, \mathrm{C} / \mathrm{D}$, central-cord-type injury dependent on specialty and spinal subspecialization, TCCI*

\begin{tabular}{|c|c|c|c|c|}
\hline \multicolumn{5}{|c|}{ Surgical timing of spinal surgeons in relation with specialty } \\
\hline & $\begin{array}{l}\text { Directly from the } \\
\text { ER }(\%)\end{array}$ & $\begin{array}{l}\text { Ultra-early }(<12 \mathrm{~h}) \\
(\%)\end{array}$ & Early $(<24$ h) $(\%)$ & Total \\
\hline \multicolumn{5}{|l|}{ ASIA A } \\
\hline Neurosurgeon & $5(16)$ & $5(16)$ & $8(26)$ & $18 / 31$ \\
\hline Orthopedic surgeon & $6(26)$ & $6(26)$ & $5(22)$ & $17 / 23$ \\
\hline Trauma surgeon & 0 & $1(20)$ & $2(40)$ & $3 / 5$ \\
\hline \multicolumn{5}{|l|}{ ASIA B } \\
\hline Neurosurgeon & $11(35)$ & $8(26)$ & $3(10)$ & $22 / 31$ \\
\hline Orthopedic surgeon & $8(35)$ & $9(39)$ & $1(4)$ & $18 / 23$ \\
\hline Trauma surgeon & 0 & $1(20)$ & $3(60)$ & $4 / 5$ \\
\hline \multicolumn{5}{|l|}{ ASIA C/D } \\
\hline Neurosurgeon & $12(39)$ & $8(26)$ & $6(19)$ & $26 / 31$ \\
\hline Orthopedic surgeon & $4(17)$ & $11(48)$ & $1(4)$ & $16 / 23$ \\
\hline Trauma surgeon & 0 & $1(20)$ & $3(60)$ & $4 / 5$ \\
\hline \multicolumn{5}{|l|}{ TCCI* } \\
\hline Neurosurgeon & $5(16)$ & $10(32)$ & $9(29)$ & $24 / 31$ \\
\hline Orthopedic surgeon & $4(17)$ & $10(43)$ & $1(4)$ & $15 / 23$ \\
\hline Trauma surgeon & 0 & $1(20)$ & $2(40)$ & $4 / 5$ \\
\hline
\end{tabular}

preferably treated less urgently. In particular, TCCI patients without spinal instability are generally treated far more conservatively.

An international survey administered before the STASCIS study showed a more urgent approach compared to our findings [12]. They found that surgeons preferred to perform surgery within $24 \mathrm{~h}$ in $85.3-96.3 \%$ of all tSCI patients and $65-87.5 \%$ within $12 \mathrm{~h}$. This is in contrast to $57-78 \%$ of Dutch surgeons who prefer to operate within $24 \mathrm{~h}$ and $30.7-56.8 \%$ within $12 \mathrm{~h}$. Other surveys that were carried out after the STASCIS study also show a less aggressive approach compared to the prior international survey [13, 14]. One of which was administered in 2013 in Canada, $50-93.3 \%$ of all surgeons preferred to perform surgery within $24 \mathrm{~h}$ and 16.6-55\% within $12 \mathrm{~h}$ [13]. Another survey performed in 2012 in the UK showed that 30-61\% of all surgeons also preferred to perform surgery within $12 \mathrm{~h}$ in tSCI [14].

We observed that the initial neurological status plays an important role in the timing of surgical intervention for tSCI. In The Netherlands, $57 \%$ of the surgeons prefer to perform surgery within $24 \mathrm{~h}$ for ASIA A, 75\% for ASIA B, and 78\% for ASIA C/D. A less urgent approach for complete spinal cord injury was also present in the UK survey from 2012 [14]. In contrary, the Canadian survey from 2013 showed that $93.3 \%$ of the surgeons preferred to perform surgery within $24 \mathrm{~h}$ for ASIA A/B, 70\% for ASIA C, and 50\% for ASIA D [13]. This suggests that patients with complete tSCI are treated different from patients with incomplete tSCI internationally [12-15]. However, although TCCI is the most common form of incomplete tSCI, these patients are treated differently in The Netherlands than patients with other forms of incomplete tSCI. Moreover, TCCI patients without spinal instability were preferably treated far less urgently $(44 \%<24 \mathrm{~h}$ vs. $60.2 \%)$. This implies that surgical treatment for patients with TCCI is heterogeneous and mostly depends on the presence of spinal instability. Surgeons have been skeptical about the role of urgent surgery for TCCI, since a substantial amount of patients with TCCI will improve spontaneously, independent of surgery [9, 16]. However, full recovery is not always present and about a fourth of all patients will experience neurological deterioration and still requires surgery. Since the distinction between TCCI and incomplete tSCI is not always clear, and discoligamentous injury is not always ruled out in the early stages by MRI, it is difficult to draw conclusions that patients with TCCI will not benefit from urgent surgery in comparison to patients with other forms of incomplete tSCI [17, 18].

Surveys are inevitably accompanied by limitations. As participants of the survey were anonymous, homogeneity of the data could not be checked, nor were analyses between centers possible. Our survey showed that non-spinal subspecialized surgeons are less inclined to perform urgent surgery than their spinal subspecialized colleagues. A possible explanation for this less urgent approach could be a different interpretation of the current literature regarding timing of surgery for tSCI. On the other hand, spinal surgeons are independent of other colleagues and, therefore, may feel more comfortable in performing this type of surgery in an urgent fashion. In this survey, the preferred timing to perform a surgical decompression might not always correspond with the actual timing in day-to-day practice [13]. 
Nevertheless, the results from our survey still reflect the current opinion on surgical timing among all Dutch surgeons involved in the care of tSCI patients.

One might question whether the evidence for the current recommended timeframe $(<24 \mathrm{~h})$ in the guidelines is robust enough, given the lack of hard evidence of superiority of this timeframe [9]. Although the STASCIS study showed a trend towards superiority of urgent $(<24 \mathrm{~h})$ surgery for neurological recovery in tSCI, its statistical power has been seriously challenged $[3,19,20]$. Nor is there clear evidence supporting our current approach, where patients with complete tSCI are managed within different timeframes than patients with incomplete tSCI. Nevertheless, a substantial amount of surgeons seems to prefer to perform surgery in an even more urgent $(<12 \mathrm{~h})$ fashion. Unfortunately, the evidence supporting urgent surgery has not become much clearer since the STASCIS study. Meanwhile, SCI patients are undergoing more operations at low-volume and nontrauma hospitals without a concomitant increase in survival, suggesting that the trend for urgent surgery might preclude immediate transfer to high-volume centers [21]. Currently, there is no robust evidence supporting the value of ultraearly surgery for incomplete tSCI, nor is there any hard evidence contradicting the benefit of urgent surgery for patients with complete tSCI.

In addition, the validity of using the ASIA scheme at the initial admission has been questioned, since a proper assessment of ASIA level is only possible after three different evaluations within $72 \mathrm{~h}$. Possibly, the increase of spinal cord edema in the first $48 \mathrm{~h}$ after trauma, as demonstrated by temporal changes of MRI characteristics, plays an important role [22-24].

To improve the neurological outcome of tSCI patients, we, therefore, think that it is of utmost importance to set up one prospective international registry on surgical timing and outcome, given the rarity of these lesions. With such a registry, we could investigate our true current surgical timing and its impact on neurological outcome to treat patients on the best individual basis.

\section{Conclusion}

The severity of initial neurological injury seems to play an important role in the decision-making of surgical timing in tSCI. Current guidelines do not discriminate on timing of operation depending on the degree of tSCI. However, in current practice, a clear distinction is made, since patients with complete tSCI and TCCI are preferably managed less urgent than patients with incomplete tSCI.

Funding No funds were received in support of this work. No relevant financial activities outside the submitted work.

\section{Compliance with ethical standards}

Conflict of interest All authors report no conflict of interest and have no financial disclosures.

Open Access This article is distributed under the terms of the Creative Commons Attribution 4.0 International License (http://creativeco mmons.org/licenses/by/4.0/), which permits unrestricted use, distribution, and reproduction in any medium, provided you give appropriate credit to the original author(s) and the source, provide a link to the Creative Commons license, and indicate if changes were made.

\section{References}

1. Post MWM, van Leeuwen CMC (2012) Psychosocial issues in spinal cord injury: a review. Spinal Cord 50(5):382-389

2. Ropper AE, Ropper AH (2017) Acute spinal cord compression. N Engl J Med 376(14):1358-1369

3. Fehlings MG et al (2012) Early versus delayed decompression for traumatic cervical spinal cord injury: results of the surgical timing in acute spinal cord injury study (STASCIS). PLoS One 7(2):e32037

4. Bourassa-Moreau E et al (2016) Do patients with complete spinal cord injury benefit from early surgical decompression? Analysis of neurological improvement in a prospective cohort study. J Neurotrauma 33(3):301-306

5. Burke JF et al (2016) 182 ultra-early ( $<12$ hours) decompression improves recovery after spinal cord injury compared to early (12-24 hours) decompression. Neurosurgery 63(Suppl 1):172

6. Biglari B et al (2016) Does surgical treatment within 4 hours after trauma have an influence on neurological remission in patients with acute spinal cord injury? Ther Clin Risk Manag 12:1339-1346

7. Jug M et al (2015) Neurological recovery after traumatic cervical spinal cord injury is superior if surgical decompression and instrumented fusion are performed within 8 hours versus 8 to 24 hours after injury: a single center experience. J Neurotrauma 32(18):1385-1392

8. Grassner L et al (2016) Early decompression ( $<8 \mathrm{~h})$ after traumatic cervical spinal cord injury improves functional outcome as assessed by spinal cord independence measure after one year. J Neurotrauma 33(18):1658-1666

9. Wilson JR et al (2016) 181 guidelines for the management of patients with spinal cord injury: the optimal timing of decompression. Neurosurgery 63(Suppl 1):172

10. Fehlings MG et al (2017) A clinical practice guideline for the management of patients with acute spinal cord injury and central cord syndrome: recommendations on the timing ( $\leq 24$ hours versus $>24$ hours) of decompressive surgery. Global Spine J 7(3 suppl):195S-202S

11. Maynard FMJ et al (1997) International standards for neurological and functional classification of spinal cord injury. American Spinal Injury Association. Spinal Cord 35(5):266-274

12. Fehlings MG, Rabin D, Sears W, Cadotte DW, Aarabi B (2010) Current practice in the timing of surgical intervention in spinal cord injury. Spine 35(21 Suppl):S166-S173

13. Glennie RA et al (2017) An analysis of ideal and actual time to surgery after traumatic spinal cord injury in Canada. Spinal Cord 55(6):618-623

14. Werndle MC et al (2012) Variability in the treatment of acute spinal cord injury in the United Kingdom: results of a national survey. J Neurotrauma 29(5):880-888 
15. Samuel AM et al (2015) Analysis of delays to surgery for cervical spinal cord injuries. Spine (Phila Pa 1976) 40(13):992-1000

16. Anderson KK et al (2015) Optimal timing of surgical decompression for acute traumatic central cord syndrome: a systematic review of the literature. Neurosurgery 77(Suppl 4):S15-S32

17. Lenehan B, Fisher CG, Vaccaro A, Fehlings M, Aarabi B, Dvorak MF (2010) The urgency of surgical decompression in acute central cord injuries with spondylosis and without instability. Spine (Phila Pa 1976) 35(21 Suppl):S180-S186

18. van Middendorp JJ, Hosman AJF, Doi SAR (2013) The effects of the timing of spinal surgery after traumatic spinal cord injury: a systematic review and meta-analysis. J Neurotrauma 30(21):1781-1794

19. van Middendorp JJ (2012) Letter to the editor regarding: 'Early versus delayed decompression for traumatic cervical spinal cord injury: results of the Surgical Timing in Acute Spinal Cord Injury Study (STASCIS)'. Spine J 12(6):540
20. Toole JEO (2014) Timing of surgery after cervical spinal cord injury. World Neurosurg 82(7-8):1-2

21. Holland CM, Mazur MD, Bisson EF, Schmidt MH, Dailey AT (2017) Trends in patient care for traumatic spinal injuries in the United States: a national inpatient sample study of the correlations with patient outcomes from 2001 to 2012. Spine (Phila Pa 1976) 42(24):1923-1929

22. Vaccaro AR et al (2013) AOSpine thoracolumbar spine injury classification system: fracture description, neurological status, and key modifiers. Spine (Phila Pa 1976) 38(23):2028-2037

23. Kalsi-Ryan S, Wilson J, Yang JM, Fehlings MG (2014) Neurological grading in traumatic spinal cord injury. World Neurosurg 82(3-4):509-518

24. Rutges JPHJ, Kwon BK, Heran M, Ailon T, Street JT, Dvorak MF (2017) A prospective serial MRI study following acute traumatic cervical spinal cord injury. Eur Spine J 26(9):2324-2332

\title{
Affiliations
}

\author{
P. V. ter Wengel ${ }^{1,7}$ (D) R. E. Feller ${ }^{1} \cdot$ A. Stadhouder ${ }^{2} \cdot$ D. Verbaan ${ }^{1,3} \cdot$ F. C. Oner ${ }^{4} \cdot$ J. C. Goslings ${ }^{5} \cdot$ W. P. Vandertop $^{1,3,6}$ \\ 1 Neurosurgical Center Amsterdam, VU University Medical \\ Center, Amsterdam, The Netherlands \\ 2 Department of Orthopedic Surgery, VU University Medical \\ Center, Amsterdam, The Netherlands \\ 3 Neurosurgical Center Amsterdam, Academic Medical Center, \\ Amsterdam, The Netherlands \\ 4 Department of Orthopedic Surgery, University Medical \\ 5 Trauma Unit, Academic Medical Center, Amsterdam, \\ The Netherlands \\ 6 Department of Neurosurgery, VU University Medical \\ Center, 2F-020, PO Box 7057, 1007 MB Amsterdam, \\ The Netherlands \\ 7 Department of Neurosurgery, Slotervaart Hospital, \\ Amsterdam, The Netherlands
} Center Utrecht, Utrecht, The Netherlands 